Volume 10, No.3, May - June 2021

International Journal of Advanced Trends in Computer Science and Engineering

Available Online at http://www.warse.org/IJATCSE/static/pdf/file/ijatcse061032021.pdf

https://doi.org/10.30534/ijatcse/2021/061032021

\title{
Competency Model of Software Developer in Thailand : A Qualitative Exploration
}

\author{
Chutchonook Charutwinyo ${ }^{1}$ \\ ${ }^{1}$ Assistant Professor, Faculty of Business Economics and Communications, Naresuan University, Thailand, \\ chutchonookc@nu.ac.th
}

\begin{abstract}
This research study aims to investigate the competency model of software developers in Thailand using the qualitative research methodology. The findings reveal the following: 1) There are two career paths for software developers, namely as entrepreneurs and as employees in various organizations, whose career development could lead to positions of executives or experts; 2) There are four competency clusters for software developers, namely Core Competency, Technical Competency, Business Competency and Teamwork Competency; 3) The assessment criteria set by workplaces for software developers are three dimensional incorporating software developers' performance, teamwork behavior, and learning and self-development; and 4) The main method for software developers' self-development is self-learning based on hands-on practices and supported by training, knowledge management and mentoring.
\end{abstract}

Key words: Competency model, Software developer, Software market, Thailand 4.0

\section{INTRODUCTION}

"Thailand 4.0" is a national policy designed to reform Thailand's economic structure and turn it into a value-based economy by such means as transforming traditional SMEs that need constant assistance from the government into smart enterprises and high-potential startups. Information technology, consequently, becomes a key driving tool in the reform's infrastructure. This inevitably makes competent human resource a vital factor for the development of new innovations and technologies to support the creation of such infrastructure and reform. However, Thailand is facing drawbacks concerning the development of its human resource to meet the goals of the "Thailand 4.0" policy. Technical staff such as scientists, engineers and analysts who comprise the most important labor group for innovation development are found to constitute only $4 \%$ of the labor market. In other words, the country is having a serious shortage of technical staff. The majority of Thai laborers lack skills related to information technology, English language, mathematics and creativity, all of which are essential for increasing productivity in the industrial sector. Trainings provided by the workplaces are relatively low in number as the entrepreneurs' readiness to embrace human resource development in the industrial sector varies vastly; large corporations with large resources are more ready to provide staff trainings than smaller organizations are.

Nowadays information technology has a role in the operation of nearly all work units in both public and private sectors and from basic to advanced operations. As a result, businesses related to information technology in Thailand have seen a continuous growth. The results of surveys conducted by Thailand Development Research Institute (TDRI) and Software Industry Promotion Agency (Public Organization) (SIPA) reveal that the growth rate of the overall software market and services in Thailand in 2014 was at $12.6 \%$ with the approximate value of 44.026 billion baht, that in 2013 was at $22.2 \%$ with the approximate value of 39.096 billion baht, and that in 2012 was at $24 \%$ with the approximate value of 31.979 billion baht. In overall, the market is projected to continue to see an annual growth in value, but not without problems and obstacles that could prove to be the most important hindrance for such growth. According to the survey results report by TDRI [23], the problems and obstacles of software industry and services in Thailand concerning the lack of quality personnel, especially in UX (User Experience) and mobile development, have stunted the growth of the production base in the country.

It can, thus, be said that human resource and information technology competency, particularly in software development, are important for driving the economy in the context of the "Thailand 4.0" policy, yet Thailand is still faced with challenges concerning the production of software developers and the development of their competency. In order to overcome these challenges, a competency model of software developers in Thailand is needed as a map for setting and controlling software developer development strategies as well as for connecting the demands of the labor market to those of technology and competency development procedure, the results of which will help sharpen Thailand's competitive edge in information technology. 


\subsection{Research Questions}

a. What is the situation of the labor market for software developers in Thailand?

b. What are the components in the competency model of software developers in Thailand?

c. How are the components in the competency model of software developers in Thailand connected?

\subsection{Objectives}

a. To study the situation of the labor market for software developers in Thailand.

b. To study the components in the competency model of software developers in Thailand.

c. To study the connections of the components in the competency model of software developers in Thailand.

\section{LITERATURE REVIEW}

Competency means desired characteristics including knowledge, skills and attitudes required to perform duties according to positions at work in order to make the work successful [2],[10],[12],[13],[14],[17].

Competency can be grouped into three clusters: 1) Knowledge, which refers to the body of knowledge required to perform duties according to one's position; 2) Skill, which refers to the ability to perform duties as a result of practice and the ability to apply one's knowledge in hands-on operations for a concrete output; and 3) Behavior, which refers to the expression or behavior required to perform duties as a result of attitudes - opinions or views - on various things affecting the behavioral display and the success of the work [1],[3],[5], [9],[16],[18],[19],[20],[22],[24]. Attitude is abstract and can be difficult to measure and manage. Behavior, on the other hand, is a concrete display of attitude and can thus be measured and managed in a more concrete manner [11].

The competency model contains three components: 1) Core Competency, which refers to the basic characteristics that a worker must have in order to achieve the goals set for his work position and that are also required for all in the same work level; 2) Functional Competency, which refers to specific characteristics that a worker must have in order to achieve the goals set for his work position according to his professional specialization and that are different from one work level to another; and 3) Management Competency, which refers to the administration and management characteristics that both executives and practitioners must have and that are different according to the roles, duties and responsibilities of the work positions [4],[6],[8],[15],[21],[25].

There have been attempts to develop competency models in information technology to serve the demands for human resource management in information technology. One of the models, namely the European Norm (EN) 16234-1 European e-Competence Framework (e-CF) offers a presentation of information technology and communication competency in five work clusters (PLAN, BUILD, RUN, ENABLE, and MANAGE), forty work competencies and five work levels. Software development is Competency 1 in the work cluster "BUILD" (B1). In B1 (Application Development), there are three work levels: Level 1 comprises the development of applications under guidance and the testing of applications and making of documents; Level 2 comprises the systematic development and checking of applications; and Level 3 comprises the creative development of applications based on suitable technical options comprising two competency groups, namely "Knowledge"[7].

Table 1: Knowledge and skills of application development in European e-Competence Framework

\begin{tabular}{|c|c|}
\hline Knowledge & Skills \\
\hline $\begin{array}{l}\text { K1 appropriate software } \\
\text { programs/modules }\end{array}$ & $\begin{array}{l}\text { S1 explain and communicate } \\
\text { the design/development to } \\
\text { the customer }\end{array}$ \\
\hline $\begin{array}{l}\text { K2 hardware components, } \\
\text { tools and hardware } \\
\text { architectures }\end{array}$ & $\begin{array}{l}\text { S2 perform and evaluate test } \\
\text { results against product } \\
\text { specifications }\end{array}$ \\
\hline $\begin{array}{l}\text { K3 functional \& technical } \\
\text { designing }\end{array}$ & $\begin{array}{l}\text { S3 apply appropriate } \\
\text { software and/or hardware } \\
\text { architectures }\end{array}$ \\
\hline $\begin{array}{l}\text { K4 state of the art } \\
\text { technologies }\end{array}$ & $\begin{array}{l}\text { S4 develop user interfaces, } \\
\text { business software } \\
\text { components and embedded } \\
\text { software components }\end{array}$ \\
\hline K5 programming languages & $\begin{array}{l}\text { S5 manage and guarantee } \\
\text { high levels of cohesion and } \\
\text { quality }\end{array}$ \\
\hline $\begin{array}{l}\text { K6 power consumption } \\
\text { models of software and/or } \\
\text { hardware }\end{array}$ & S6 use data models \\
\hline K7 DBMS & $\begin{array}{l}\text { S7 perform and evaluate test } \\
\text { in the customer or target } \\
\text { environment }\end{array}$ \\
\hline $\begin{array}{l}\text { K8 operating systems and } \\
\text { software platforms }\end{array}$ & $\begin{array}{l}\text { S8 cooperate with } \\
\text { development team and with } \\
\text { application designer }\end{array}$ \\
\hline \multicolumn{2}{|l|}{$\begin{array}{l}\text { K9 integrated development } \\
\text { environment (IDE) }\end{array}$} \\
\hline \multicolumn{2}{|l|}{$\begin{array}{l}\text { K10 rapid application } \\
\text { development (RAD) }\end{array}$} \\
\hline \multicolumn{2}{|l|}{ K11 IPR issues } \\
\hline \multicolumn{2}{|l|}{$\begin{array}{l}\text { K12 modeling technology } \\
\text { and languages }\end{array}$} \\
\hline \multicolumn{2}{|l|}{$\begin{array}{l}\text { K13 interface definition } \\
\text { languages (IDL) }\end{array}$} \\
\hline K14 security & \\
\hline
\end{tabular}




\section{RESEARCH METHODOLOGY}

This study employed the qualitative research methodology based on Grounded Theory and undertook First Cycle Coding and Second Cycle Coding to analyze relations and explain their meanings. First, codes were set according to the research objectives. Then, data were analyzed by assigning codes to the data units, the process of which is called First Cycle Coding, according to the designed structure. Next, the First Cycle Codes were condensed into the Second Cycle Codes, and concepts were developed simultaneously. In this step, the Second Cycle Codes and the concepts were added to and improved upon in order to attempt to explain the data and all the phenomena. After that, the relations among the concepts were organized with the aim to explain both old and new data and phenomena. Finally, a model was presented.

The population in this study comprised business owners, executives and experts in software development in Thailand (from both Thai and foreign organizations). The sample group was derived by means of purposive sampling and snowball sampling. The data were collected by means of in-depth interviews using semi-structured interview questions. The data were simultaneously analyzed using a software program during the process of the data collection based on Grounded Theory until theoretical saturation was determined. The data collection and analysis finished after twelve informants from the sample group had been interviewed.

\section{RESULTS}

\subsection{The situation of the software market, labor market and career paths of software developers in Thailand}

At present, the software market in Thailand can be divided into two main areas, namely software development and distribution and software development and services. The software development and distribution by Thai companies are faced with numerous limitations such as a low rate of consumer acceptance compared to that of foreign software and limited software contents designed for a small-scale market in Thailand. These limitations result in lower software prices which affect the software quality. The software development and services, on the other hand, are seeing an increase in competition from foreign service providers. The fact that Thai consumers are generally unwilling to pay high prices for software and that the pressure to reduce costs to maintain competitiveness is increasing have led the entrepreneurs to adjust to the aspect concerning software development and services rather than the traditional software development and distribution, as evident in the following interviews: (7 first cycle codes, 3 second cycle codes)
"A Thai software must be cheaper than a foreign software, not by $20 \%$ but by 5 times. And they won't buy cheaper stuff; they will buy more expensive stuff ... The companies that produce the software can't make good products because that means higher costs. They make things that are as good as their prices so that they can keep their business running ... I think that Thailand should provide a common platform where people can work together and share resources."

(Interviewee 1)

"SMEs in our country don't have enough money for employment ... Some companies do offer software development positions, but those are few and far between." (Interviewee 4)

There is still a high demand for software developers in the labor market in Thailand even though there is competition from foreign workforce. Foreign entrepreneurs can offer software developers higher remunerations than Thai entrepreneurs can because they are able to provide software services to a larger market. Some organizations take advantage of the lower labor cost in Thailand and make it their base for software development and services provided to customers in other countries, as evident from the following interviews:(16 first cycle codes, 5 second cycle codes)

"The trends now are still upward because many work sectors want to switch from human labor to software and hardware, especially AI, as in image processing and smart farming."

(Interviewee 3)

"Foreign companies employ Thai people for two reasons. They make Thailand a production base for exporting goods because Thailand is a good place to visit and the labor is cheap. Foreigners have cheap products in a good place. Advantages in all aspects. And then they export the products."

(Interviewee 4)

Thailand lacks competent software developers. Although educational institutes have produced many information technology graduates, most are not sufficiently competent to handle jobs in software development. These challenges are the result of the production process - upstream, midstream and downstream - of software development personnel in educational institutes that are facing numerous problems themselves such as learners who are uninterested in a career in software development since they regard it as a difficult job that requires a high level of effort, program contents that do not meet the demands of modern workplaces and technologies since it is a field of work that constantly experiences rapid technological changes, and graduates who switch to other fields of work since they perceive the work of software development as stressful and see opportunities to earn equal or more money doing other jobs that are less stressful, as 
evident in the following interviews:(31 first cycle codes, 4 second cycle codes)

"I don't have enough developers. This is a big problem for me. The ones I have are not sufficiently competent. Another problem I have is with freelancers who drop the jobs midway."

(Interviewee 5)

"Large companies are invariably short of software developers. For some programs, my boss actually asked Human Resource Division to help recruit qualified personnel. It was quite difficult to get someone with the right qualifications. It took us over a year to find the person."

(Interviewee 6)

There are two career paths for software developers in Thailand: 1) as entrepreneurs; and 2) as employees in various organizations in which the mid-career development offers two career tracks: 2.1) as executives; and 2.2) as experts. To be an expert requires specialized professional skills including software development skills. However, positions for software development experts are generally available only in large organizations whose core business is software development. The three stages of career development: Entry-Level (Inventor/Junior-Senior Developer), Mid-Level (Entrepreneur/Senior Developer, System Analyst/Specialist) and High-Level (CEO/Project Manager/Expert) are shown in Figure 2 and in the following interviews:(9 first cycle codes, 3 second cycle codes)

"An employee starts as a junior programmer. When he matures into more responsibilities, he will become a senior programmer who can now mentor the juniors. After that, he will become a team leader who supervises both the juniors and the seniors. Eventually, he will get to the position of Solution Architecture who designs all sorts of platforms."

(Interviewee 9)

"An employee starts as a junior developer. It takes around four years to become a senior developer. Many organizations provide options for career development. One of them is to be an IT executive. If you follow this track, you can become an assistant manager and a manager. Another track is to be a specialist and then become an expert."

(Interviewee 11)

\subsection{The components in the competency model of software developers in Thailand}

The components in the competency model of software developers in Thailand can be categorized into four groups: Core Competency, Technical Competency, Business Competency, and Teamwork Competency. Each group contains three forms of competency: Knowledge, Skill and Behavior.

Core Competency comprises seven areas of competency: 1) Communication (Skill) is vital for the work of software development that requires teamwork and coordination among team members and with clients/service receivers. Software developers, therefore, must have communication skills to work with their team members and their clients/service receivers. 2) English Language (Skill) must be cultivated by software developers for learning, problem-solving and professional communication as learning resources and knowledge required to solve problems are mostly available in English. In addition, software developers nowadays are often required to work with foreign team members and clients/service receivers. 3) Learning (Skill) is essential for software developers as they work in a field that requires constant learning to keep pace with technological changes. This inevitably affects their career advancement. 4) Thinking (Skill) is required in the work of software development that involves problems related to coding. The process of analyzing and solving problems, therefore, is important for achieving fast and efficient solutions, and analytical thinking is likewise an important skill for software developers. 5) Problem Solving (Skill) is important for software developers who must deal with problems of coding, teamworking and coordinating with clients/service receivers. 6) Activeness (Behavior) is an important quality of software developers since they generally meet constant challenges and are, therefore, required to learn new things constantly. 7) Responsibility (Behavior) is required since software developers must work as a team with their team members and with their clients/service receivers. To be responsible for their assignments and for their commitment to clients/service receivers is essential and will affect both the software developers' professional success and advancement and the team's achievement, as shown in Figure 1 and in the following interviews:(126 first cycle codes, 7 second cycle codes)

"Software developers must have presentation skills so that they can communicate with customers. It won't do to always say no to customers ... Now software developers with over 10 years of work experience can't even communicate with salespeople because they never have to do it. All they do is work at their desks ... Another big problem that I have is the lack of communication among team members. How can a team work together without talking to one another? The team leader loses control over individuals. The developers' ego is also a problem. If they are about the same age, they won't acknowledge that the others are better. That can also affect work."

(Interviewee 5)

"No matter how much they studied in college, they still have to learn more after graduation ... They have to learn constantly because their work requires constant adjustments. For example, a finished project that is in the process of system 
testing may present a problem that they've never known of before. Then they'll have to study it and find a solution."

(Interviewee 2)

"In addition, the work requires responsibility, punctuality, the ability to learn new things and activeness."

(Interviewee 1)

Technical Competency comprises four areas of competency, namely 1) Programming Languages and Platforms (Knowledge and Skill): Software developers are required to possess skills to operate both Object Oriented Programming (OOP) languages and software development platforms. Initially, a software developer must be skilled in one programming language which will enable him to learn other programming languages. Developers must not bind themselves to only one programming language but should learn and adjust to different languages as required by the limitations and contexts of their work and the changes of the technology. Popular languages and platforms are, for instance, Java Script, Python, Agular and Laravel. 2) Database and Data Usage (Knowledge and Skill): Software developers must be able to use both SQL databases (for jobs that employ old technologies or small-sized data) and No-SQL databases (for jobs that employ new technologies or large-sized data) for different types of work. Developers are also required to be skilled in data usage such as data analysis, data mining, data science and machine learning. 3) Security (Knowledge and Skill): The increase in both transaction data and IT criminal activities results in the increase in users' concerns regarding digital security. Software development, therefore, must pay special attention to the aspect of security in order to boost clients/service receivers' confidence. 4) Software Development Process (Knowledge and Skill): The software development process now functions as a continual cycle aiming to enhance efficiency, meet users' needs and compete better in the market. This emphasizes the software development process and methods that can create endless streams of new software. Software developers must, consequently, have the knowledge and skills to work efficiently as a team, as shown in Figure 1 and in the following interviews:(134 first cycle codes, 31 second cycle codes)

"There are many hackers now. Programming and databases are the basic elements. Security is an add-on."

(Interviewee 9)

"Now the data science track is on the rise. It requires skills in several fields: mathematics, business and programming ... If you want to be a step ahead, you must also know about performance, performance improvement and program testing."

(Interviewee 11)
Business Competency is essential to software developers as an additional competency that provides the developers with a value added from the very beginning of their career and that will prove to be increasingly important when the developers' career advances to the levels of executives and entrepreneurs. Business Competency comprises three areas of competency, namely 1) Business Strategies and Consumer Behavior (Knowledge and Skill): Nowadays some software developers are required to work with clients/service receivers from the start of the software development process. The understanding of business strategies and consumer behavior and the ability to make analyses in these aspects, therefore, will help the developers to better comprehend both the needs of their clients/service receivers and the competition in the global market. 2) Business Process (Knowledge and Skill): From the mid-level operation onwards, the work of software developers will involve more and more of the process of software quality enhancement which includes analyzing, planning, improving and assessing. The understanding of the business process will enable the developers to improve the software quality more effectively as well as to give better recommendations to clients/service receivers. 3) Business Opportunity (Knowledge and Skill): As executives and entrepreneurs, an important skill lies in the ability to search for and make use of business opportunities and to develop new software and services to increase the organization's competitiveness and sustainability. Developers who aim to reach this high-level operation - except those in the track of experts - must possess this skill, as shown in Figure 1 and in the following interviews:(27 first cycle codes, 7 second cycle codes)

"Developers today and tomorrow must know about business. Having knowledge of the technology but nothing at all of business ... will make it difficult to sell products. Although we have the products and the ideas, we wouldn't know who to sell them to. If we have business knowledge as an add-on, we will be able to go further."

(Interviewee 2)

"Software developers must also take a moment for self-reflection. If they continue to work only on software development, their perspective regarding user-based development will be narrow. Developers who have business and research skills are paid more ... These skills increase the developers' value, so business skills and programming skills give them professional advantages."

(Interviewee 10)

Teamwork Competency is important because software developers in today's context work in a team both as team members and, as their career progresses, as team leaders. Moreover, if their clients/users are presented as organizations, coordinating with them as a team is inevitable. Teamwork 
Competency, therefore, is vital for software developers. It comprises three areas of competency, namely 1) Team Membership (Skill and Behavior): This is a competency required of entry-level software developers who are expected to operate as team members in activities such as giving opinions, sharing information and listening to others' opinions. 2) Team Leadership (Skill and Behavior): This is a competency required of mid-level software developers who are expected to operate as team leaders in activities such as motivating, managing conflicts and rewarding. 3) Team Management (Skill and Behavior): This is a competency required of high-level software developers who are expected to operate as team managers at both team and organization levels in activities such as coordinating between different teams, managing resources between different teams and creating shared goals and concepts, as shown in Figure 1 and in the following interviews:(11 first cycle codes, 7second cycle codes)

"Mostly they need the teamwork skills because each project will assign a team to work on it. If developers can't work as a team, they won't be able to communicate with the other team members and will be miserable at work ... I would like the universities to help develop students by adding communication, teamwork and language skills."

(Interviewee 3)

"A skill that must be instilled is the ability to be open to others' opinions. In our company, we work mostly in teams, so it's very important to listen to others and to think about what they've said. When problems arise, they must be dealt with. We must be alert while working."

(Interviewee 10)

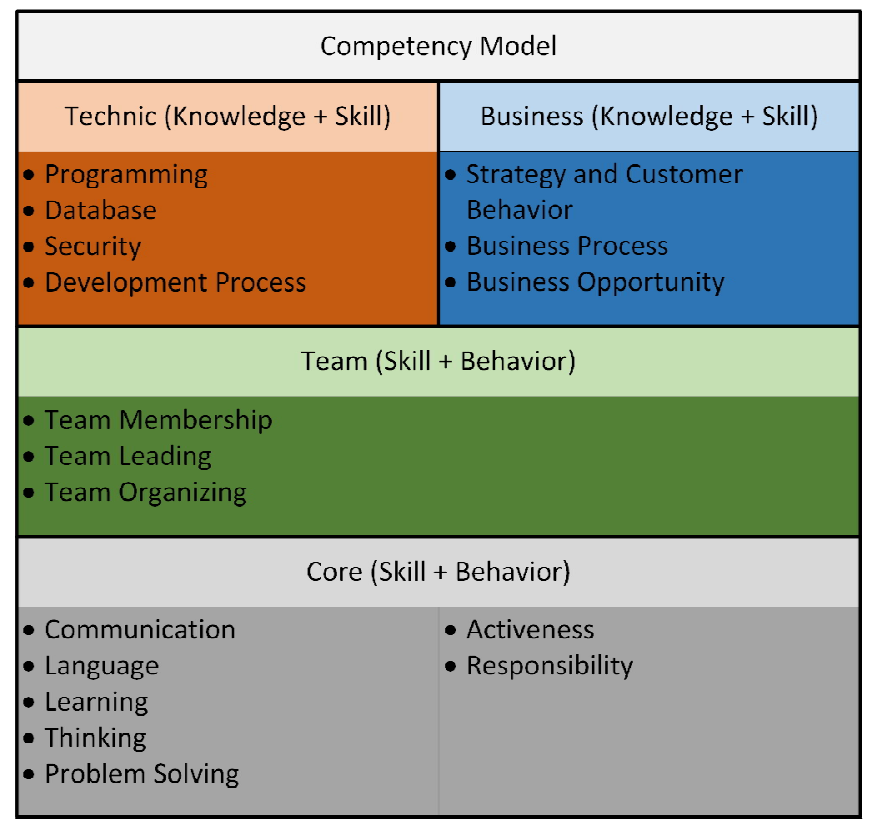

Figure 1: Competency model
4.3 The connection between the components in the competency model, performance evaluation and competency development

Core Competency comprising 7 areas of competency, namely 1) Communication (Skill), 2) English Language (Skill), 3) Learning (Skill), 4) Thinking (Skill), 5) Problem-Solving (Skill), 6) Activeness (Behavior), and 7) Responsibility (Behavior), will affect the other three competency clusters, namely Technical Competency, Business Competency, and Teamwork Competency in terms of software developers' competency level, competency development and performance. Furthermore, Technical Competency and Teamwork Competency have direct effects on software developers' output and performance. Business Competency, on the other hand, gives a value-added to Technical Competency. This relationship is significant in terms of both performance evaluation and competency development of software developers. At present, companies assess the performance of their software developers based on their output mainly as a resultof their technical and business competencies with considerations regarding their teamwork behavior as well as their learning and self-development, as shown in Figure 1 and in the following interviews:(7 first cycle codes, 2 second cycle codes)

"I look at their output. Normally when we give assignments, we'll also give deadlines. If they meet the deadlines, they fulfill $70 \%$ of the total score. Another $30 \%$ is for the soft skills. If they are competent at work but unable to communicate with their team members resulting in working solo and not as a team, or they cause problems when they talk to others, they are given the score accordingly in this $30 \%$ portion."

(Interviewee 9)

"Software development is a kind of art. If the developers are not in the right state of mind, they can't be productive. Therefore, I focus on the results ... I mainly look at the output. On the other hand, the developers must also be able to work in a team."

(Interviewee 1)

The development of software developers' competency and output cannot be achieved by looking at only Technical Competency, Business Competency and Teamwork Competency. Considerations must be made regarding primary problematic areas in Core Competency. For example, some developers are unable to produce good works because they cannot finish the programing in a timely manner. If this problem is handled superficially, the company might try to solve the problem by sending the developers to a programing camp. This will not necessarily solve the problem. However, when Core Competency is taken into consideration, the 
company might discover that the developers in fact lack Learning Competency (Skill) as well as English Language Competency (Skill), which make them unable to learn from the abundant resources available on the Internet. The company might discover further that the developers also lack Responsibility (Behavior) to take charge of their own self-development. Tackling these problems by developing suitable competencies will bring about successful solutions. At the present time, most organizations support the development of their software developers' Technical Competency by various means such as providing trainings, knowledge management, mentoring and hands-on practices. Nevertheless, it must be said that the main approach for competency development remains that of self-learning. This means that software developers must rely on their activeness and learning skills as tools to enhance their Technical Competency with the help of hands-on practices, as evident in the following interviews:(22 first cycle codes, 4second cycle codes)

"The best approach is hands-on practice. I start with a lecture, not a long one, just to instruct how to do something. What I usually do is that I ask the software developer to have lunch with me. I buy him lunch and teach him for 10 minutes each day. Then I give a coding problem for him to solve. He must write real codes ... Real learning takes place with actual practice. When he reaches a certain level of competency, I will give him an easy project to do. It may not be a real project ... I use the mentoring system. He sits with his mentor while programming whatever job that comes in at the time." (Interviewee 1)

"They must do real work. I've done it since the time I was doing my first degree... Learning requires practicing. Programing is like studying mathematics. It requires a lot of practice."

(Interviewee 11)

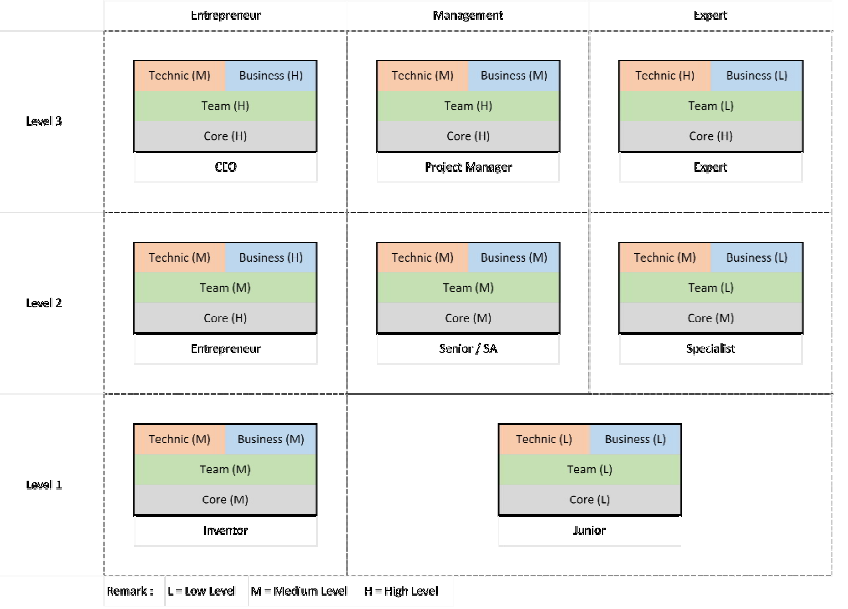

Figure 2: Competency model and career path

\section{CONCLUSION AND DISCUSSION}

\subsection{Conclusion}

From the results of the study, it could be concluded that the software market of Thai entrepreneurs in Thailand still presents several limitations such as a low rate of consumer acceptance as compared to that of foreign software and limited software contents designed for a small-scale market in Thailand. On the contrary, the labor market in Thailand presents a continual high demand for software developers and offers them higher renumerations than the average rate for work in the field of information technology. Competent software developers are still in short supplies due to the inability of educational institutes to produce graduates that meet the demands of the labor market. There are two career paths for software developers: 1) as entrepreneurs; and 2) as employees in various organizations in which the career development offers two career tracks: 2.1) as executives; and 2.2) as experts, which are generally needed only in large organizations whose core business is software development. The career development can be divided into three stages: Entry-Level (Inventor/Junior-Senior Developer), Mid-Level (Entrepreneur/Senior Developer, System Analyst/Specialist) and High-Level (CEO/Project Manager/Expert).

The competency model of software developers consists of four related competency clusters, namely Core Competency, Technical Competency, Business Competency and Teamwork Competency. Core Competency affects the other three competency clusters while Technical and Teamwork Competencies have direct effects on software developers' performance and Business Competency gives a value added to Technical Competency.

\subsection{Discussion}

For the components of the competency model, this study's findings regarding the four competency clusters correspond to those of previous literature and studies that classified the competencies into Core Competency, Managerial Competency and Functional Competency [4],[6],[8],[15],[21],[25]. This study, nevertheless, further divides Functional Competency into Technical Competency and Business Competency in order to bring more clarity to the analysis. In addition, this study adjusts Managerial Competency into Teamwork Competence since teamwork features significantly in the line of work of software developers, and the adjustment is expected to give a clearer picture to the evaluation of their performance and the development of their competency.

In terms of the forms of competency, this study opts to replace Attitude with Behavior and, consequently, to present 
competencies as Knowledge, Skill and Behavior, which are different from the forms of competency presented in previous literature and studies [1],[3],[5],[9],[16],[18],[19],[20],[22],[24]. Since expressions and behaviors are concrete and can be measured and managed more firmly than attitudes which are abstract and difficult to measure and manage. This finding should likewise enable organizations to evaluate and develop their software developers in a more concrete manner.

When the results of the present study are compared with the European Norm (EN) 16234-1 European e-Competence Framework (e-CF), it is found that this study presents competency clusters (Core Competency, Technical Competency, Business Competency and Teamwork Competency) with more coverage than those of e-CF which only focus on Technical Competency. Moreover, this study's findings present competency in the forms of Knowledge, Skill and Behavior whereas those of e-CF only focus on Knowledge and Skill. Furthermore, most competency models currently available have been developed to serve the structures of large organizations where work is clearly divided. Business organizations in Thailand that deal with software development, however, are mostly small companies with relatively few employees who are required to work in more than one field. The employees must, therefore, possess a wider range of skills and offer competitiveness in terms of work flexibility and adjustment.

\subsection{Suggestions}

The present study's findings reveal the competency model of software developers in terms of components and their connection. These findings suggest opportunities for future studies; for example, a study of the details of the components in each competency cluster, a survey study to confirm the structural relations among components in each competency cluster, and a study of the details regarding the evaluation and development of each competency cluster.

\subsection{Limitations}

The present study was conducted based only on the opinions and experience of business owners, executives and experts in the field of software development in Thailand. It did not investigate the opinions of other stakeholders in the software industry in Thailand such as personnel staff, employees and educational institutes.

\section{REFERENCES}

1. Athey, T. R., \& Orth, M. S. (1999). Emerging competency methods for the future. Human Resource Management, 38, 215-226.
2. Boyatzis, R. (2007). Competencies in the 21st century. Journal of Management Development, 27(1), 5-12.

3. Campion, M. A., Fink, A. A., Ruggeberg, B. J., Carr, L., Phillips, G. M., \& Odman, R. B. (2011). Doing competencies well: Best practices in competency modeling. Personnel Psychology, 64, 225-262.

4. Carmuffo, A., \&Comacchio, A. (2005). Linking intellectual capital and competitive advantage: A cross-firm competence model for northeast Italian SMEs in the manufacturing industry. Human Resource Development International, 8, 361-377.

5. Chen, H. C., \& Naquin, S. S. (2006). An integrative model of competency development, train- ing design, assessment center, and multi-rater assessment. Advances in Developing Human Resources, 8, 265-282.

6. Dooley, K. E., Lindner, J. R., Dooley, L. M., \&Alagaraja, M. (2004). Behaviorally anchored com- petencies: Evaluation tool for training via distance. Human Resource Development International, 7, 315-332.

7. European Committee for Standardization. (2014). The European e-Competence Framework 3.0. Bruxelles: CEN-CENELEC publications.

8. Goldstein, I. L., \& Ford, J. K. (2002). Training in organizations (4th ed.). Belmont, CA: Wadsworth.

9. Gregory, W. S. (2012). A Critical Review of the Science and Practice of Competency Modeling. Human Resource Development Review, 12(1), 86-107.

10. Guthrie, H. (2009). Competence and Competency-based Training: What the Literature Says. Adelaide: National Centre for Vocational Education Research Ltd.

11. Hayton, J. C., \& McEvoy, G. M. (2006). Competencies in practice: An interview with Hanneke C. Frese. Human Resource Management, 45, 495-500.

12. Hornby, D., \& Thomas, R. (1989). Toward a Better Standard of Management. Personnel Management, 21(1), 52-55.

13. Jacobs, R. (1989). Getting the Measure of Management Competence. Personnel Management, 21(6), 32-37.

14. Klemp, G. O. (1980). The assessment of occupational competence. Washington, D.C: National Institute of Education.

15. Kujawińska, A., Vogt, K., \&Hamrol, A. (2016). The role of human motivation in quality inspection of production processes. Advances in Intelligent Systems and Computing, 490, 569-579.

16. Mansfield, R. S. (1996). Building competency models: Approaches for HR professionals. Human Resource Management, 35, 7-18.

17. McClelland, D. C. (1973). Testing for Competence Rather Than for Intelligence. American Psychologist, 28(1), 1-14.

18. Mirabile, R. J. (1997). Everything you wanted to know about competency modeling. Training and Development, 51(8), 73-77. 
19. Parry, S. B. (1996). The quest for competencies. Training, 33, 48-54.

20. Parry, S. B. (1998). Just what is a competency? (And why should you care?). Training, 35, 58-64.

21. Rothwell, W. J., \& Kazanas, H. C. (1992). Mastering the instructional design process. San Francisco: Jossey Bass.

22. Soderquist, K. E., Papalexandris, A., Ioannou, G., \&Prastacos, G. (2010). From task-based to competency-based: A typology and process supporting a critical HRM transition. Personnel Review, 39, 325-346.

23. Thailand Development Research Institute. (2013). Results of the Software Market and Software Services 2012/2013 and Forecast 2014. Bangkok: Software Industry Promotion Agency (Public Organization).

24. Tobias, L., \& Dietrich, A. (2003). Identifying employee competencies in dynamic work domains: Methodologicalconsiderations and a case study. Journal of Universal Computer Science, 9(12), 1500-1518.

25. Vatankhah, B. R., Hashemipour, M., \& Guerra-Zubiaga, D. A. (2013). Developing a competency-assisted collaborative promotion modeling framework in higher education. Procedia-Social and Behavioral Sciences, 107, 112-119. 